\title{
DFT Study of The Interaction Characteristics Between the Organic Matter and Minerals In Coal- Series Kaolin
}

\section{Teng Huang ( $\sim$ huanggua1984@163.com )}

Southwest University of science and technology

\section{Lei Shaomin}

WHUT: Wuhan University of Technology

He Zhihao

Chengdu University of Technology

\section{Man Chen}

Southwest University of Science and Technology

Men Li

Southwest University of Science and Technology

\section{Research Article}

Keywords: coal-series kaolin, organic matter, adsorption, kaolinite, DFT

Posted Date: October 1st, 2021

DOI: https://doi.org/10.21203/rs.3.rs-933519/v1

License: (c) (1) This work is licensed under a Creative Commons Attribution 4.0 International License. Read Full License 


\section{Abstract}

Coal-series kaolin is an associated mineral resource in coal mining process, often contains organic components and other discoloring impurities, which may lower the quality and limit the industrial application. However, the occurrence, stability of organic component and how they affect the surface physical and chemical properties of coal-series kaolin is known little. In this article, several representative organic components have been enrolled for analyzing the interactions with different minerals of the coalseries kaolin. Results shows that the unsaturated double bonds may be easier to adsorb with kaolinite, and the energy on $\mathrm{C}_{20} \mathrm{H}_{40}$ is the least among all the compositions. Among the different crystal planes of kaolinite, the (001) surface may possess higher adsorption characteristic on the organic molecules, which may be consistent with the crystal face index of the kaolinite. While the adsorption energy between the organic molecules and the impurities in coal-series kaolin was positive all the time, suggesting that the organic matter could only adsorb with kaolinite compared with the impurities such as pyrite, quartz and anatase. Calculations of state density also showed that the displacement of the energy band for kaolinite may shift to the lower state after adsorbed with different organic matter, also a rearrangement and significant increase of peak values for the state density may occur after adsorption. This study aims to provide a theoretical basis for the occurrence state and stability differences of different organic matters on the coal-series kaolin, also further solve the long-term problems of restricting the whiteness and comprehensive utilization of coal-series kaolin resources.

\section{Introduction}

As a co-associated mineral associated with coal stratum, the coal-series kaolin has abundant reserves in China. For the special properties such as strong plasticity, high temperature resistance and good dispersibility, the coal-series kaolin has been applied in many industrial fields[1 3]. Owing to the presence of humus, kerogen and other organic matter components, the whiteness and quality of coal-series kaolin may be decreased[4,5]. Typically, The free organic matter often occurs in the pores between minerals[6,7], which can be separated from minerals by soxhlet extraction, while the enclosed organic matter will bind to the minerals by chemical adsorption, such as adsorbed in the interlayer of clay minerals. For the tight combination, organic matter may be difficult to separate from the clay minerals[6,8,9], which also reflects the influence of different mineral properties on the enrichment of organic matter[10]. Kai wei[11] found that the adsorption behavior of lysine onto clay minerals followed the order: saponite > montmorillonite > chlorite > kaolinite > illite, XRD (X-ray diffraction囚results indicated that the adsorption of lysine on saponite and montmorillonite occurred mainly in the interlayer of clay minerals, while lysine was mainly present on the surface of chlorite, kaolinite and illite. Ru Xin[12] found that the adsorption affinity of

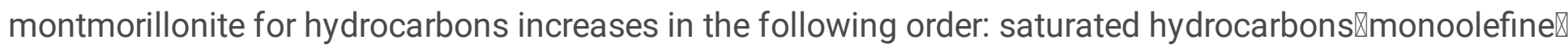
alkadiene $₫$ mono-aromatic hydrocarbon $『$ polycyclic aromatic hydrocarbon. Chen[13] proposed that the adsorption mechanism of humic acid on kaolinite and montmorillonite may be different, kaolinite is dominated by ligand exchange, while montmorillonite is dominated by cation exchange. 
Compared with the inorganic mineral components, the content of organic matter in the coal-series kaolin is relatively low, and mostly exists in the form of amorphous and highly insoluble macromolecular humus, to separate and characterize the carbon matter in the kaolin is relatively difficult[14 15]. The interaction mechanism between organic matter and inorganic minerals in coal-series kaolin may be also rarely involved, which could also become one of the important factors restricting the whiteness and deep processing of coal-series kaolin. Therefore, to carry out specific research on the interaction between organic matter and the different mineral compositions has become a pressing task[11,16].

With the rapid development of quantum chemistry theory and improvement of testing technique, research on the stability of organic composition and the interrelationship with the minerals make them possible[17 19]. Based on our previous work, we have preliminarily analyzed the composition and structural units of organic matter in the coal-series kaolin of Yichang, China[1,20]. So in this work, on account of the mineral composition in the coal-series kaolin, we will build the adsorption models between typical organic molecule and the coal-series kaolin by Density functional theory (DFT) methods, so as to reveal the occurrence state and stability differences of different organic matters on the coal-series kaolin, fully understand the interaction mechanism between organic matter and different minerals in coal series kaolin, which can be beneficial to the enrichment and recovery of organic matter, so as to further solve the bottleneck problem of restricting the whiteness and comprehensive utilization of coal-series kaolin[19,21,22].

\section{Materials And Methods}

\subsection{Materials and Characterization}

Raw coal-series kaolin was supplied by Yichang, Hubei Province, China. The mineral characterization, soxhlet tests of organic matter with chloroform were described in our previous studies, while the product of extraction was characterized by gas chromatograph/mass spectroscopy (GC/MS) analyzer (7890A5975C; Agilent, USA) as shown in Fig. 1 and Appendix [1, 20].

As shown in Table 1 and Fig. 2, the main phase of raw ore was kaolinite, with a content of approximately $85 \%$. The main impurities were pyrite, quartz, anatase and illite, each are less than $4 \%$. The chloroform extraction product of organic matter in the coal-series kaolin mainly consisted of three kinds of compounds: aliphatic hydrocarbons, aromatic hydrocarbons and oxygenated compounds, and the maximum content was $n$-tetracosane $\left(\mathrm{C}_{24} \mathrm{H}_{50}, 11.95 \%\right)$, followed by $\mathrm{n}$-tricosane $\left(\mathrm{C}_{23} \mathrm{H}_{48}, 5.7 \%\right)$, $\mathrm{n}$ triacontane $\left(\mathrm{C}_{30} \mathrm{H}_{62}\right.$, approximately $\left.5 \%\right)$, and 1-octadecene $\left(\mathrm{C}_{18} \mathrm{H}_{36}\right.$, approximately $\left.3 \%\right)$. While the content of aromatic hydrocarbon and oxygenated chemicals are relatively less[1,20].

To simplify the subsequent calculations, several higher content molecules, namely, $\mathrm{C}_{30} \mathrm{H}_{62}, \mathrm{C}_{24} \mathrm{H}_{50}$, $\mathrm{C}_{20} \mathrm{H}_{40}, \mathrm{C}_{18} \mathrm{H}_{36}, \mathrm{C}_{15} \mathrm{H}_{24} \mathrm{O}(\mathrm{BHT})$ will be taken into account in analyzing the interactions with different minerals, so as to analyze the adsorption characteristics between organic matter and kaolinite in the 
following research[23, 24], while the calculation results for the total energy after geometric optimization was shown in Table 2.

\subsection{Models and Calculation method}

Kaolinite is a layered clay mineral composed of the alternate layers of tetrahedral $\mathrm{SiO}_{4}$ and octahedral $\mathrm{AlO}_{6}$ periodically. Using the structural parameters of the Inorganic Crystal Structure Database (ICSD), different crystal models were then established using Materials Studio.

In this study, the adsorption behavior of organic component and different minerals in the coal-series kaolin was studied using DFT method, while the calculation was carried out by $\mathrm{Dmol}^{3}$ modules. The equilibrium configuration at the lowest energy was determined by geometry optimization, combined with the analysis of the adsorption energy and surface charge distribution.

Molecular structure models of different minerals were adopted as shown in Fig. 3(considering the convergence of structure, we use pyrite $2 * 1 * 1$ supercell), and the lattice planes were split by geometrically optimized structures, all the calculations were carried out by $\mathrm{Dmol}^{3}$ modules using the spin polarization method[15, 22, 25], the Becke-Perdew (BP) correction approximation under the generalized gradient approximation (GGA) was used in the geometric optimization calculation, the calculation accuracy was set as fine, unless otherwise specified, the smearing value was set as 0.005 . The total energy values at different sites were also calculated, so as to compare the stability of organic composition and the interrelationship with different minerals[23, 24, 26].

\subsection{Calculation method of adsorption energy}

The adsorption energies between organic matter and different minerals in the coal-series kaolin were calculated by the Eq. (1):

$\mathrm{E}_{\text {ads }}=\mathrm{E}_{\text {total }}-\left(\mathrm{E}_{\text {organics }}+\mathrm{E}_{\text {minerals }}\right)(1)$

where $\mathrm{E}_{\text {total }}$ is the total energy of geometric optimization after surface adsorption, $\mathrm{E}_{\text {organics, }} \mathrm{E}_{\text {minerals }}$ are the total energy of organic molecule and the surface of different minerals, respectively before adsorption. With less adsorption energy, the adsorbability is more stable $[24,27,28]$.

\section{Results And Discussion}

\subsection{Adsorption models of different crystal planes on kaolinite}

The usual crystal planes of kaolinite are (001), (110), (002), (010), (111), etc[1, 21]. To simplify adsorption models and analyze the occurrence state differences with the organic matters, several crystal planes of kaolinite were discussed as shown in Fig. 4. 
As(001)surface corresponding to the maximum characteristic peak of kaolinite, taking the crystal face 0001 \as an example, the calculations result of the adsorption energy between the organic molecules and kaolinite was shown in Table 3.

Different functional groups of organic matter in coal-series kaolin may present diverse adsorption characteristics when adsorbed on kaolinite (001) surface. Taking alkane as an example, with the increasing of carbon chain length, the adsorption energy between alkanes and kaolinite (001) surface may be slightly increased $\left(\mathrm{C}_{30} \mathrm{H}_{62}>\mathrm{C}_{24} \mathrm{H}_{50}\right)$, suggesting that the adsorption may be more difficult to occur on the long-chain alkane, such as $\mathrm{C}_{30} \mathrm{H}_{62}$ discussed in this article, the adsorption energy may turn to be positive. For the structure containing olefins $(C=C)$, the unsaturated double bonds make the molecular structure possess relatively strong activity, which are easier to adsorb on kaolinite. The adsorption energy of olefin $\left(\mathrm{C}_{18} \mathrm{H}_{36}, \mathrm{C}_{20} \mathrm{H}_{40}\right)$ may be lower when compared with alkane, and the energy on $\mathrm{C}_{20} \mathrm{H}_{40}$ is the least $(-7.3271729 \mathrm{eV})$ among all the compositions. While the adsorption of alkanes and oxygenated-compounds $\left(\mathrm{C}_{15} \mathrm{H}_{24} \mathrm{O}\right)$ with kaolinite may be more difficult to occur for their relatively stable structure $[29,30,31]$.

As the adsorption on $\mathrm{C}_{30} \mathrm{H}_{62}$ is relatively hard, we will further discuss the rest of the functional groups $\left(\mathrm{C}_{24} \mathrm{H}_{50}, \mathrm{C}_{18} \mathrm{H}_{36}, \mathrm{C}_{20} \mathrm{H}_{40}, \mathrm{C}_{15} \mathrm{H}_{24} \mathrm{O}\right)$, so as to compare the adsorption energy between the functional groups and different crystal planes of kaolinite. The comparison of the adsorption energy was shown in Table 3.

The adsorption energy on different crystal planes is rarely identical for the same functional group. For the kaolinite (001), the adsorption energy on $\mathrm{C}_{20} \mathrm{H}_{40}, \mathrm{C}_{18} \mathrm{H}_{36}, \mathrm{C}_{24} \mathrm{H}_{50}$ is much lower when compared with the rest of crystal planes, while kaolinite (200) may be easier to adsorb on $\mathrm{C}_{15} \mathrm{H}_{24} \mathrm{O}$. The adsorption energy between $\mathrm{C}_{20} \mathrm{H}_{40}$ and kaolinite (001) is the least among all the structure models $(-7.3271729 \mathrm{eV})$, suggesting that the (001) surface may possess higher adsorption characteristic on the organic molecules, which may be consistent with the crystal face index of the kaolinite [28, 31, 32].

\subsection{Adsorption models of different minerals}

As discussed above, the coal-series kaolin often contains pyrite, quartz, anatase and other impurities, which may also interact with the organic matters. To fully understand the interaction mechanism and stability differences with the minerals in coal-series kaolin, several crystal planes of such minerals were presented to explore the adsorption between the organic matters and the impurities. To simplify the adsorption models, taking the maximum characteristic peaks of such minerals as shown in Fig. 5, we will further investigate the adsorption characteristic between the organic molecules and different impurities of coal-series kaolin, The calculations result was shown in Table 5.

The adsorption energy between the organic molecules and the impurities in coal-series kaolin was positive all the time, suggesting that the organic matter may be very hard to adsorb on pyrite, quartz. While the absolute values of adsorption energy on anatase were always the maximum compared with the rest of minerals, indicated that the organic matter was least likely to interact with the anatase[26, 27, 33]. 


\subsection{Calculation of State density}

State density is always used for the visual analysis of electronic structure, and the adsorption process, variation of electron orbits could also be differentiated by density of states (DOS) and partial density of states (PDOS) [23, 26, 34].

Taking olefin as an example, DOS for kaolinite when adsorbed with different organic molecules was shown in Fig. 6. The initial value of energy is $-20.88 \mathrm{eV}$ before adsorption, while on $\mathrm{C}_{20} \mathrm{H}_{40}$ and $\mathrm{C}_{18} \mathrm{H}_{36}$, the energy is decreased to $-22.51,-22.11 \mathrm{eV}$, respectively. The displacement of the energy band may shift to the lower state after adsorption. New characteristic peaks were present in the energy band nearly 14 -8eV, and the curves on $\mathrm{C}_{20} \mathrm{H}_{40}$ and $\mathrm{C}_{18} \mathrm{H}_{36}$ may shift to the lower energy when compared with kaolinite, especially in the energy band $-10 \sim 0 \mathrm{eV}$, which also confirmed that a rearrangement of the electron clouds and strong chemical bonding between kaolinite and the organic molecules. The peak values of state density after adsorption may also increase dramatically, the value on $\mathrm{C}_{20} \mathrm{H}_{40}$ may reach to 70.4 electrons/eV, higher than that on $\mathrm{C}_{18} \mathrm{H}_{36}$ and kaolinite before adsorption, verifying that the effect on adsorption between kaolinite and $\mathrm{C}_{20} \mathrm{H}_{40}$ can be more significant, which may be consistent with the adsorption energy shown in Table.4[24, 35, 36].

\section{Conclusions}

This paper mainly analyzes the stability differences of typical organic component and how they affect the surface physical and chemical properties of coal-series kaolin by DFT method. Combined with calculation of the state density, the micro-mechanism of the interaction between the kaolinite and different organic molecules was further analyzed, the conclusions are as follows:

(1) Different functional groups in coal-series kaolin may present diverse adsorption characteristics when adsorbed on kaolinite (001) surface, and the energy on $\mathrm{C}_{20} \mathrm{H}_{40}$ is the least among all the compositions. While the adsorption energy on different crystal planes is also rarely identical for the same functional group, (001) surface may possess higher adsorption characteristic on the organic molecules, which may be consistent with the crystal face index of the kaolinite.

(2) The adsorption energy between the organic molecules and the impurities in coal-series kaolin was positive all the time, suggesting that the organic matter may be very hard to adsorb on such minerals discussed in this article, and the organic matter was least likely to interact with the anatase.

(3) The displacement of the energy band for kaolinite may shift to the lower state after adsorbed with different organic matter. A rearrangement and significant increase of peak values for the state density may occur after adsorption, the value on $\mathrm{C}_{20} \mathrm{H}_{40}$ may reach to 70.4 electrons/eV, higher than that on $\mathrm{C}_{18} \mathrm{H}_{36}$ and kaolinite before adsorption, which confirm that strong chemical bonding between organic molecules and kaolinite. 


\section{Declarations}

\section{Acknowledgements}

This work was financially supported by Academician workstation of Yichang Huilong Science and Technology Co., Ltd. Association of Science and Technology of Hubei Province. Thanks to Foundation $17 z x 7140$ of Southwest University of Science and Technology, also appreciate the supercomputing supporting of Mineral Processing "211" Key Laboratory of Wuhan University of Technology, Chengdu University of Technology and National Supercomputing Beijing\&Shenzhen Center.

\section{References}

1. Huang T, Lei S, Liu Y, Fan (2018) Yanming. Composition, purification, and identification of carbon matter in coal-series kaolin by COD analysis. Res Chem Intermed 44(11):6497-6513

2. Dedzo GK, Detellier C (2016) Functional nanohybrid materials derived from kaolinite. Appl Clay Sci 130:33-39

3. Gendy El, Khiari A, Bettaieb R, Marlin F, Dufresne N (2014) Alain. Preparation and application of chemically modified kaolin as fillers in Egyptian kraft bagasse pulp. Appl Clay Sci 101:626-631

4. Yuan S, Li Y, Han Y, Gao P (2018) Effects of carbonaceous matter additives on kinetics, phase and structure evolution of coal-series kaolin during calcination. Appl Clay Sci 165:124-134

5. Wang Lanyun,Xu, Yongliang JShuguang,Yu, Minggao C, Tingxiang Z, Weiqing Wu, Zhengyan (2012) Kou Li-wen .Imidazolium based ionic liquids affecting functional groups and oxidation properties of bituminous coal. Saf Sci 50(7):1528-1534

6. Du Jiazong H, Bei C, Jingong L, Tianzhu L, Qing XZ (2020) Separation and Detection Methods of Organic Acids with Different Properties in Source Rocks. Geological Journal of China Universities 26(5):540-548

7. Angst G, Mueller KE, Kögel-Knabner I et al (2017) Aggregation controls the stability of lignin and lipids in clay-sized particulate and mineral associated organic matter. Biogeochemistry 132(3):307324

8. Zhu X, Cai J, Wang X et al (2014) Effects of organic components on the relationships between specific surface areas and organic matter in mudrocks. International Journal of Coal Geolotry 133:24-34

9. Zhu X, Cai J, Wang G et al (2018) Role of organo-clay composites in hydrocarbon generation of shale. Int J Coal Geol 192:83-90

10. Zhu Xiaojun C, Jingong (2012) Progress and significance of research on relation between specific surface area and organic matter in argillaceous source rocks. Oil Gas Geology 33(3):375-384

11. Wei K, Yuanfeng C, Jingong C, Junfeng J (2018) Comparative Study of the Adsorption of L-lysine on the Different Clay Minerals. Geological Journal of China Universities 24(5):671-680 
12. Ru Xin (2013) Study on the experiment and molecular simulation of oil shale pyrolysis. Ji Lin University

13. Chen HF, Koopal LK, Xiong J et al (2017) Mechanisms of soil humic acid adsorption onto montmorillonite and kaolinite. Journal of Colloid Interface Science 504:457-467

14. Underwood T, Erastova V, Greenwell HC (2016) Wetting effects and molecular adsorption at hydrated kaolinite clay mineral surfaces. J Phys Chem C 120(21):11433-11449

15. Lee SG, Choi J, Koh W, Jang SS (2013) Adsorption of $\beta$-D-glucose and cellobiose on kaolinite surfaces: Density functional theory (DFT) approach. Appl Clay Sci 71:73-81

16. Wang, Dan (2015) Experimental investigation of interactions between dissimilatory iron reducing bacteria and organic clay mineral. China University of Geosciences (Beijing)

17. Kasprzhitskii A, Lazorenko G, Yavna V, Daniel Ph (2016) DFT theoretical and FT-IR spectroscopic investigations of the plasticity of clay minerals dispersions. J Mol Struct 1109:97-105

18. Zhang Z, Liu J, Yang Y, Shen F, Zhang Z (2018) Theoretical investigation of sodium capture mechanism on kaolinite surfaces. Fuel 234:318-325

19. Pragathi Darapaneni O, Kizilkaya, Craig Plaisance and James A. Dorman. Adsorption of Polarized Molecules for Interfacial Band Engineering of Doped TiO2 Thin Films, Langmuir 2020, 36, 58395846

20. Huang T, Lei S, Liu Y, Ji (2017) Mengjiao, Fan, Yanming. Beneficiation and influencing factors of coal-series kaolin for the reduction of COD. Appl Clay Sci 138:34-39

21. Chen Jun,Min Fanfei,Liu Lingyun (2019) Density Function Study on Microscopic Interactions Between Fine Particles of Coal and Kaolinite in Coal Slurry Water. Materials Reports 33(8):26772683. (in Chinese)

22. Mermer A, Bayrak H, Alyar S, Alagumuthu M, Synthesis (2020) DFT calculations, biological investigation, molecular docking studies of $\beta$-lactam derivatives. J Mol Struct 1208:127891

23. Orazi V, Juan A, González EA, Marchetti JM, Jasen PV (2020) DFT study of ethanol adsorption on $\mathrm{CaO}\left(\begin{array}{ll}0 & 0\end{array}\right)$ surface. Appl Surf Sci 500:144254

24. Wu Y, Zhang L, Liu Y, Qu Y (2018) Adsorption mechanisms of metal ions on the potassium dihydrogen phosphate $\left(\begin{array}{lll}1 & 0 & 0\end{array}\right)$ surface: A density functional theory-based investigation. J Colloid Interface Sci 522:256-263

25. Patterson MC, Thibodeaux CA, Kizilkaya O, Kurtz RL, Poliakoff E, Sprunger PT (2015) Electronic Signatures of a Model Pollutant-Particle System: Chemisorbed Phenol on TiO2 (110). Langmuir 31:3869-3875

26. Xing J, Wang C, Zou C, Zhang (2020) Yue.DFT study of Se and SeO2 adsorbed on CaO (l 001$)$ surface: Role of oxygen. Appl Surf Sci 510:145488

27. Babaei Z, Najafi Chermahini A, Dinari M (2020) Glycerol adsorption and mechanism of dehydration to acrolein over TiO2 surface: A density functional theory study. J Colloid Interface Sci 563:1-7 
28. Bao Li S, Liu J, Guo L, Zhang (2018) Interaction between low rank coal and kaolinite particles: A DFT simulation. Appl Surf Sci 456:215-220

29. Swagat S, Rath S, Singh DS, Rao BB, Nayak BK, Mishra (2017) Adsorption of heavy metals on a complex Al-Si-O bearing mineral system: Insights from theory and experiments. Sep Purif Technol 186:28-38

30. Li J, Xin He,Emeka Oguzie, and Cheng Peng, Molecular Bonding of Predissociative CO on Fe(100): Molecular Orbital Perspective, Langmuir 2019, 35, 16407 - 16415

31. Wang X, Huang Y, Zhong Z, Pan Z, Liu C (2016) Theoretical investigation of cadmium vapor adsorption on kaolinite surfaces with DFT calculations. Fuel 166:333-339

32. Ható Z, Makó, Kristóf T (2014) Water-mediated potassium acetate intercalation in kaolinite as revealed by molecular simulation. J Mol Model 20(3):1-10

33. Huang T, Lei S, Liu J, Mengjiao Y, Fan Y (2017) Density functional theory study of oxygen atom adsorption on different surfaces of pyrite. Journal of Wuhan University of Technology-Mater Sci Ed 32(6):1464-1469

34. Zhang S, Liu, Qinfu, Gao F, Li X, Liu, Cun, Li H, Boyd SA, Johnston, Cliff T, Teppen, Brian J (2017) Mechanism associated with kaolinite intercalation with urea: Combination of infrared spectroscopy and molecular dynamics simulation studies. J Phys Chem C 121(1):402-409

35. He J, Zhang H, Yue T, Wei S, Yuehua Hu, and Chenyang Zhang.Effects of Hydration on the Adsorption of Benzohydroxamic Acid onthe Lead-Ion-Activated Cassiterite Surface: A DFT Study, Langmuir 2021, 37, 2205-2212

36. Luo J-H, Hu A-M, Wang X-L, Zhang Y-H, Li Z-S (2013) Adsorption of water on NaNO3(001) surface from first-principles calculations. J Colloid Interface Sci 393(1):340-346

\section{Tables}

Table 1. XRF analysis for the coal-series kaolin

\begin{tabular}{|c|c|c|c|c|c|}
\hline Components & $\mathrm{SiO}_{2}$ & $\mathrm{Al}_{2} \mathrm{O}_{3}$ & $\mathrm{Fe}_{2} \mathrm{O}_{3}$ & $\mathrm{SO}_{3}$ & $\mathrm{TiO}_{2}$ \\
\hline content $₫ w t . \% \rrbracket$ & 45.67 & 33.34 & 1.88 & 2.82 & 2.11 \\
\hline Comp & $\mathrm{Na}_{2} \mathrm{O}$ & $\mathrm{P}_{2} \mathrm{O}_{5}$ & $\mathrm{~K}_{2} \mathrm{O}$ & $\mathrm{MgO}$ & LOI \\
\hline content $₫ w t . \% \rrbracket$ & 0.07 & 0.03 & 0.33 & 0.02 & 13.75 \\
\hline
\end{tabular}

Table 2. Calculation results for the total energy of different organic molecules 


\begin{tabular}{|ll|}
\hline Composition & $\begin{array}{l}\text { Total energy after } \\
\text { geometric optimization/ Ha }\end{array}$ \\
\hline n-triacontane $\left(\mathrm{C}_{30} \mathrm{H}_{62}\right)$ & -1180.8029074 \\
\hline n-tetracosane $\left(\mathrm{C}_{24} \mathrm{H}_{50}\right)$ & -944.8829222 \\
\hline eicosane $\left(\mathrm{C}_{20} \mathrm{H}_{40}\right)$ & -786.3701218 \\
\hline octadecene $\left(\mathrm{C}_{18} \mathrm{H}_{36}\right)$ & -707.7301284 \\
\hline butylated hydroxytoluene $\left(\mathrm{C}_{15} \mathrm{H}_{24} \mathrm{O}\right)$ & -661.4216147 \\
\hline
\end{tabular}

Table 3. Calculations results of the adsorption energy between the organic molecules and kaolinite (1

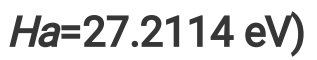

\begin{tabular}{|lllll|}
\hline \multirow{2}{*}{ alkane } & Composition & $\mathrm{E}_{\text {total }}(\mathrm{Ha})$ & $\mathrm{E}_{\text {ads }}(\mathrm{Ha})$ & $\mathrm{E}_{\text {ads }}(\mathrm{eV})$ \\
& n-tetracosane $\left(\mathrm{C}_{24} \mathrm{H}_{50}\right)$ & -7924.0358314 & -0.1071998 & -2.9170566 \\
\cline { 2 - 5 } olefin & n-triacontane $\left(\mathrm{C}_{30} \mathrm{H}_{62}\right)$ & $-\mathbf{8 1 5 9 . 7 9 3 6 8 2 5}$ & $\mathbf{0 . 0 5 4 9 3 4 3}$ & $\mathbf{1 . 4 9 4 8 3 9 2}$ \\
\cline { 2 - 5 } & 1-octadecene $\left(\mathrm{C}_{18} \mathrm{H}_{36}\right)$ & --7686.8806292 & -0.1047914 & -2.8515207 \\
\hline \multirow{2}{*}{$\begin{array}{l}\text { oxygenated } \\
\text { compounds }\end{array}$} & 1-eicosene $\left(\mathrm{C}_{20} \mathrm{H}_{40}\right)$ & $-\mathbf{7 7 6 5 . 6 8 5 0 9 9 7}$ & $-\mathbf{0 . 2 6 9 2 6 8 5}$ & $\mathbf{- 7 . 3 2 7 1 7 2 9}$ \\
& $\left(\mathrm{C}_{15} \mathrm{H}_{24} \mathrm{O}\right)$ & -7640.4970603 & -0.0297362 & -0.8091636 \\
\hline
\end{tabular}

Table 4. Comparison of the adsorption energy between the organic molecules and different crystal planes of kaolinite

\begin{tabular}{|cllll|}
\hline Composition & \multicolumn{2}{l}{$\mathrm{E}_{\text {ads }}(\mathrm{eV})$} & & \\
& kaolinite (001) & kaolinite (002) & kaolinite (200) & kaolinite (022) \\
\hline $\mathrm{C}_{20} \mathrm{H}_{40}$ & -7.3271729 & -2.1271614 & -1.9461566 & -2.4252868 \\
\hline $\mathrm{C}_{18} \mathrm{H}_{36}$ & -2.8515207 & -0.5149077 & -1.4085301 & -0.5398551 \\
\hline $\mathrm{C}_{24} \mathrm{H}_{50}$ & -2.9170566 & 5.4803297 & -2.5214083 & -0.9654605 \\
\hline $\mathrm{C}_{15} \mathrm{H}_{24} \mathrm{O}$ & -0.8091636 & -1.7319049 & -4.7619841 & -1.5297433 \\
\hline
\end{tabular}

Table 5. Comparison of the adsorption energy between the organic molecules and different minerals 


\begin{tabular}{|cllc|}
\hline Composition & \multicolumn{2}{l|}{$\mathrm{E}_{\text {ads }}(\mathrm{eV})$} & \\
\cline { 2 - 4 } & $\begin{array}{l}\text { Pyrite (200) } \\
\text { (smearing0.05) }\end{array}$ & Anatase (101) & Quartz (101) \\
& 10.9443462 & 12.8069638 & 12.6677176 \\
$\mathrm{C}_{20} \mathrm{H}_{40}$ & 9.7466173 & 13.1943670 & 2.6454488 \\
\hline $\mathrm{C}_{18} \mathrm{H}_{36}$ & 9.0073979 & 14.4211685 & 11.5632912 \\
\hline $\mathrm{C}_{24} \mathrm{H}_{50}$ & 3.3933868 & 10.0763352 & 11.0359153 \\
\hline $\mathrm{C}_{15} \mathrm{H}_{24} \mathrm{O}$ & & & \\
\hline
\end{tabular}

Figures

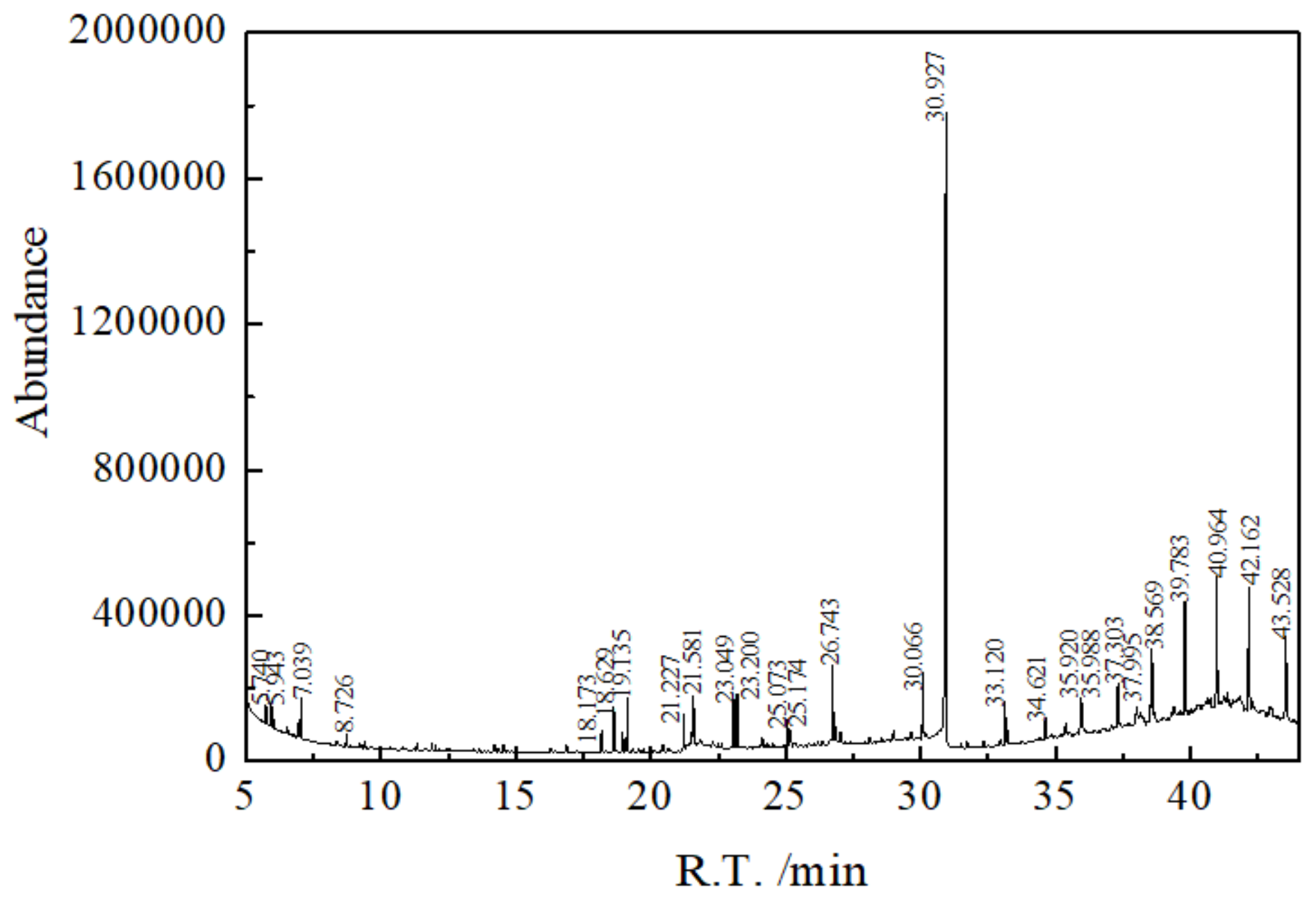

Figure 1

GC-MS spectrum of soxhlet extraction product 


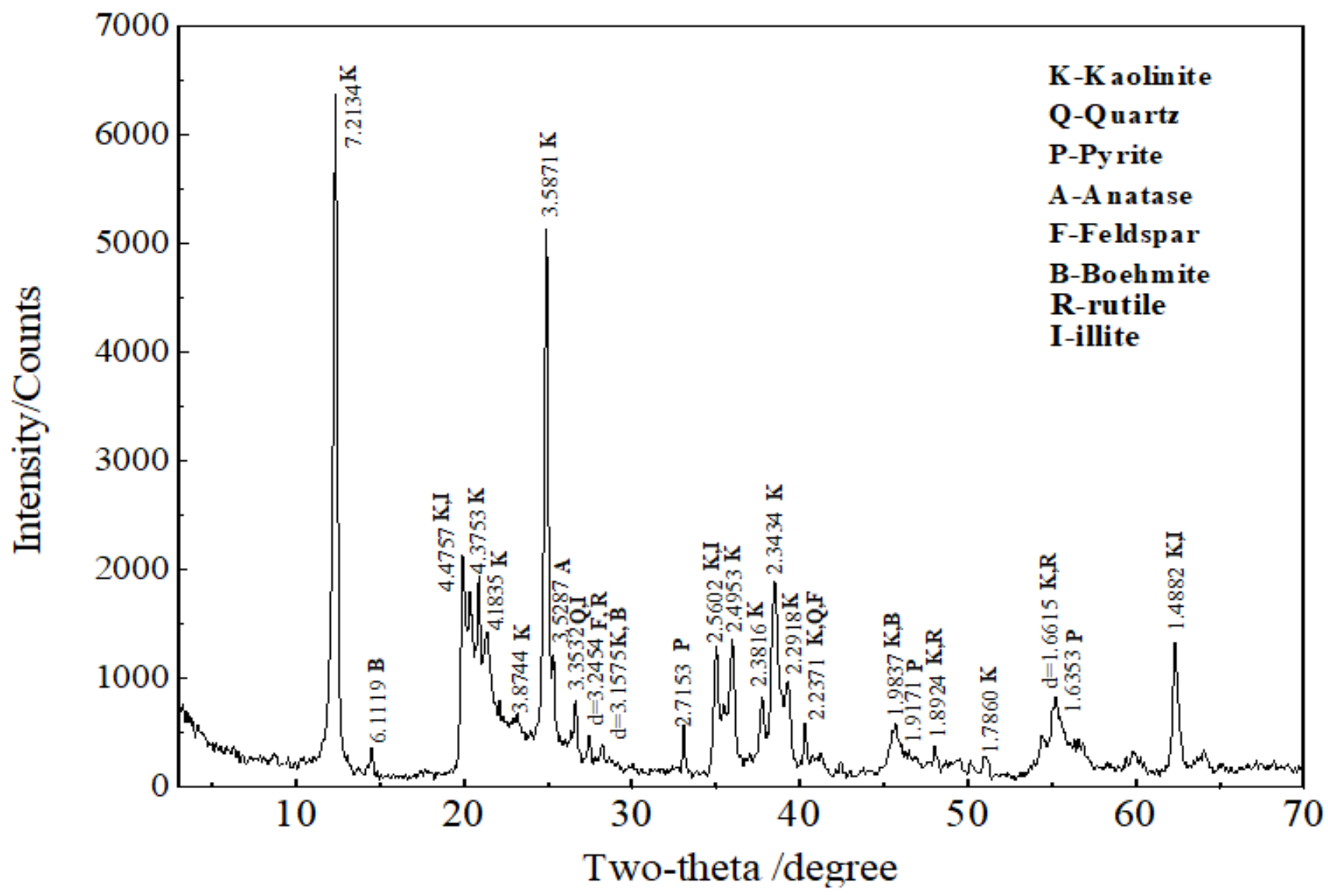

Figure 2

XRD pattern of coal-series kaolin 


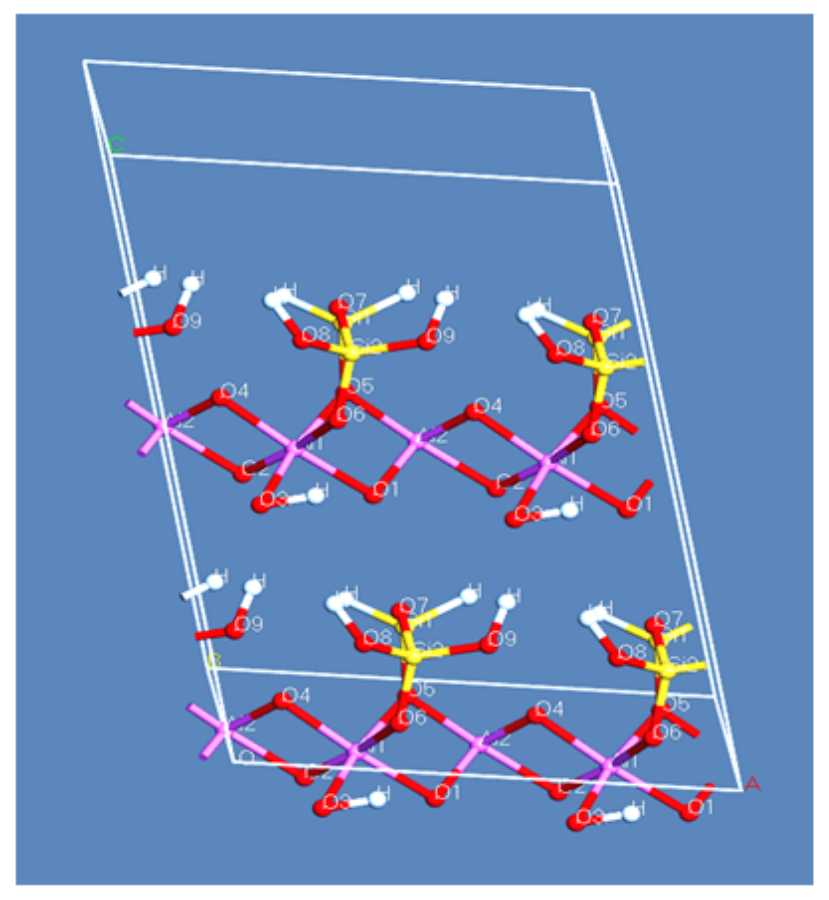

(a) Kaolinite $(2 * 1 * 2)$

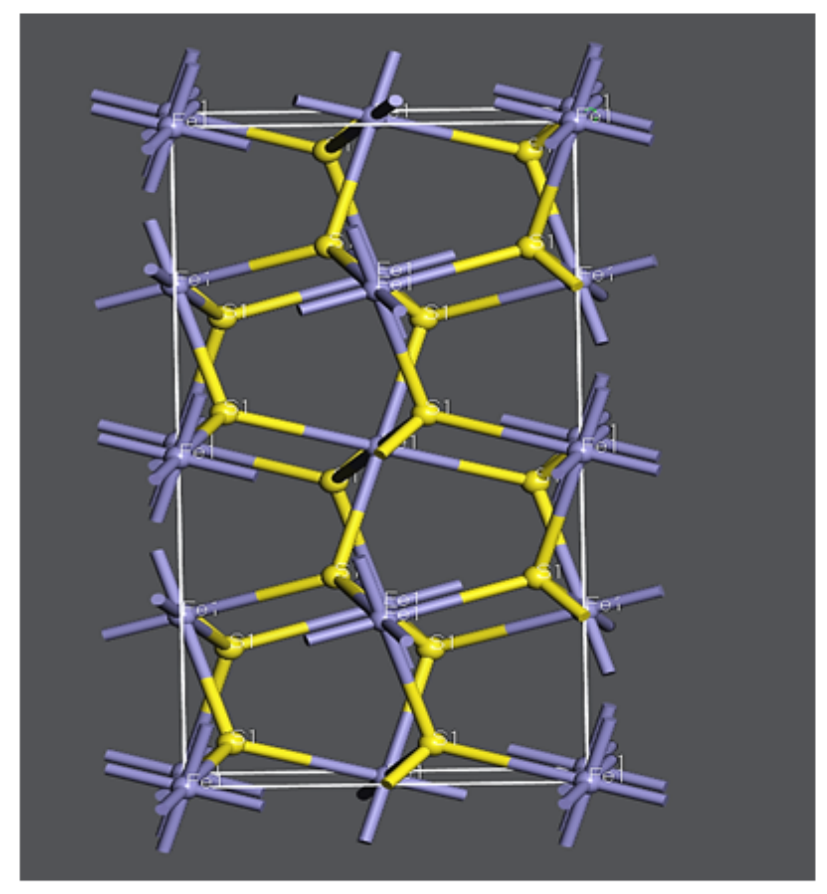

(c) Pyrite $(2 * 1 * 1)$

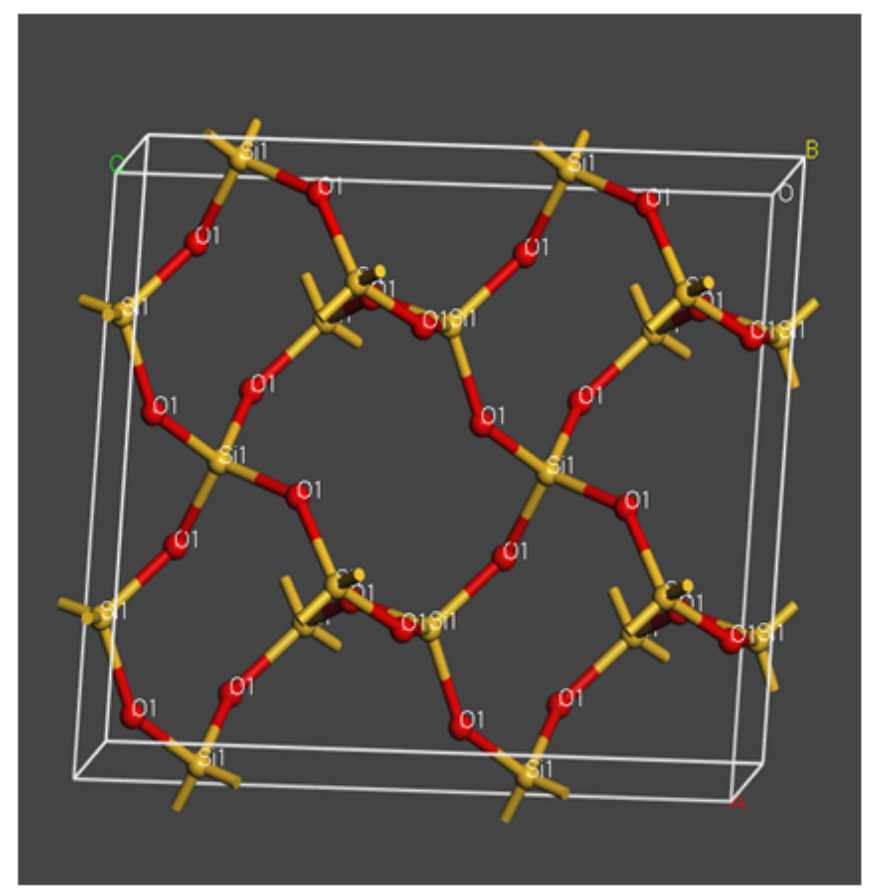

(b) Quartz $(2 * 1 * 2)$

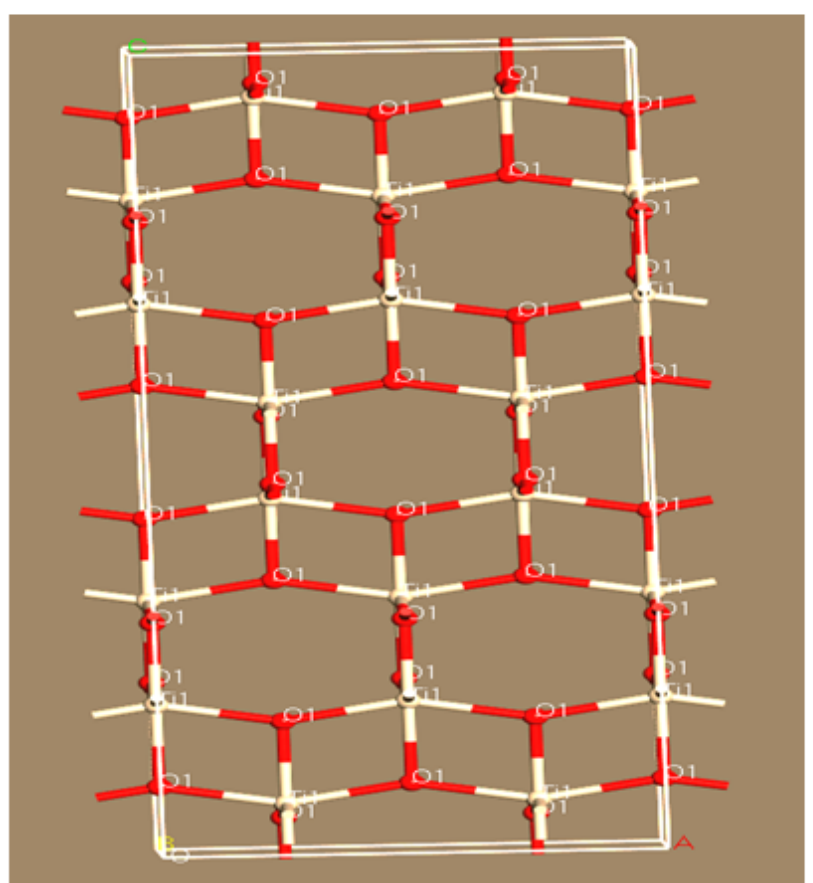

(d) Anatase $(2 * 1 * 2)$

\section{Figure 3}

Molecular structure models of different minerals in the coal-series kaolin 


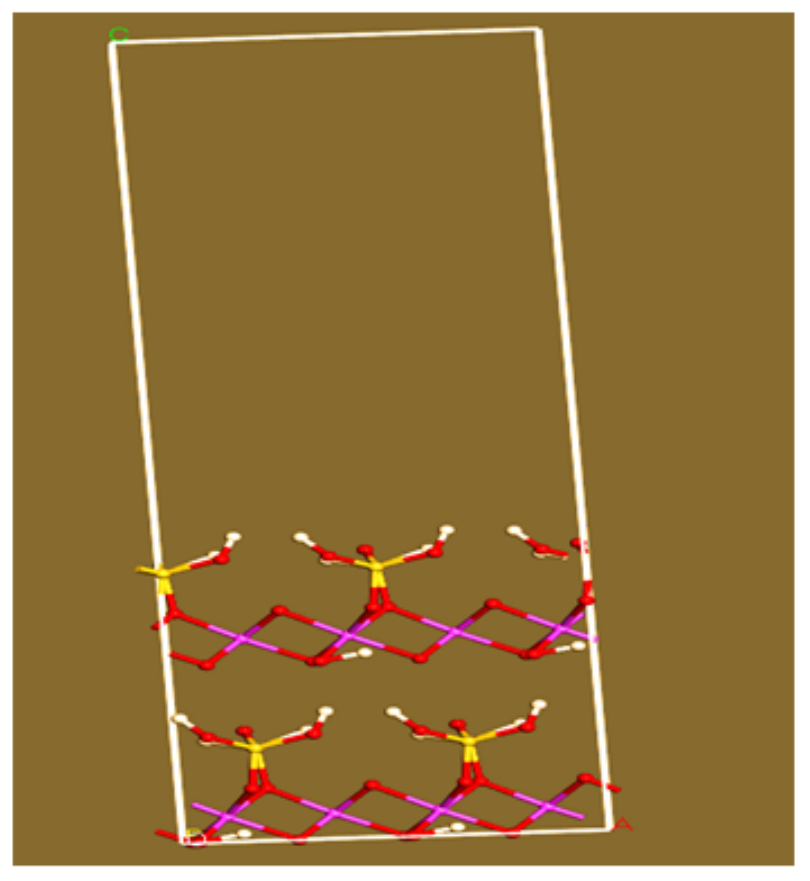

(a) Kaolinite (001) surface

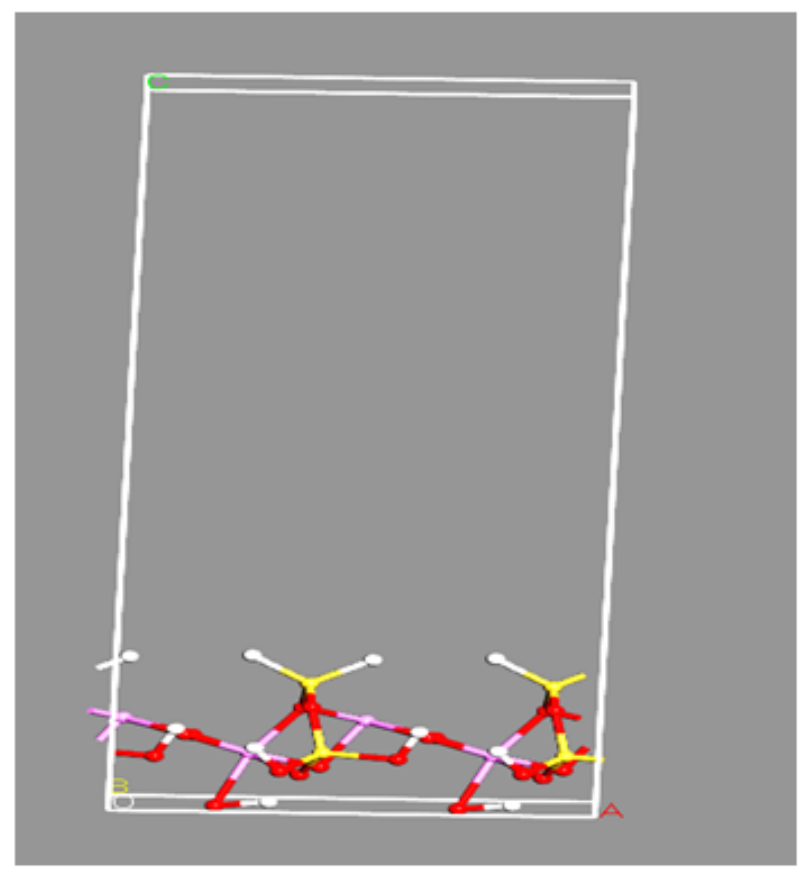

(c) Kaolinite (022) surface

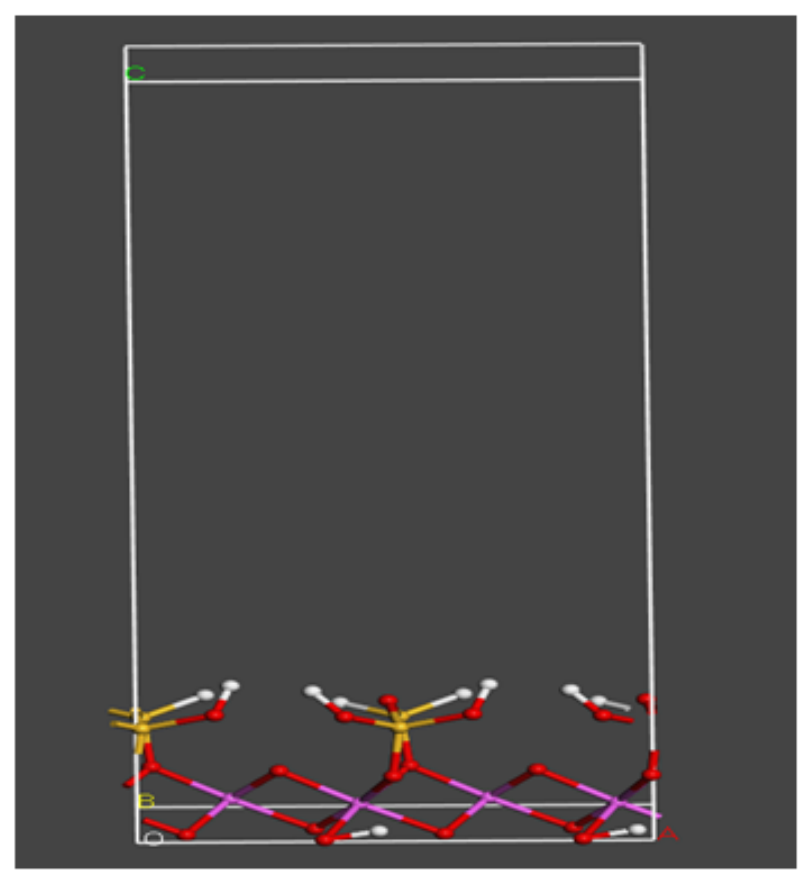

(b) Kaolinite (002) surface

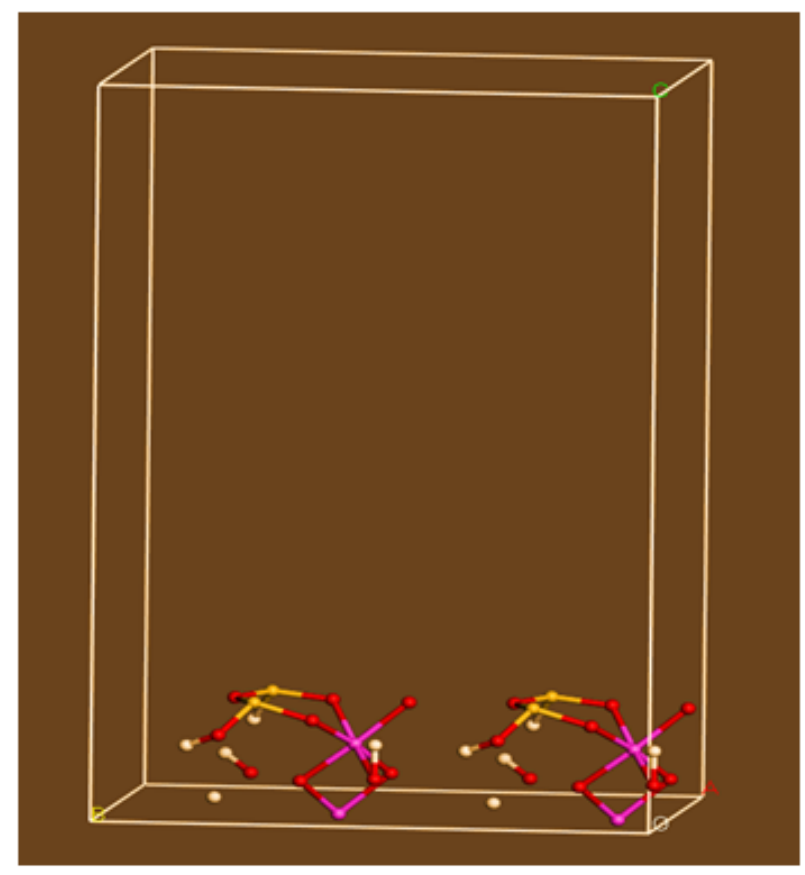

(d) Kaolinite (200) surface

\section{Figure 4}

Several crystal planes of kaolinite discussed in the text 


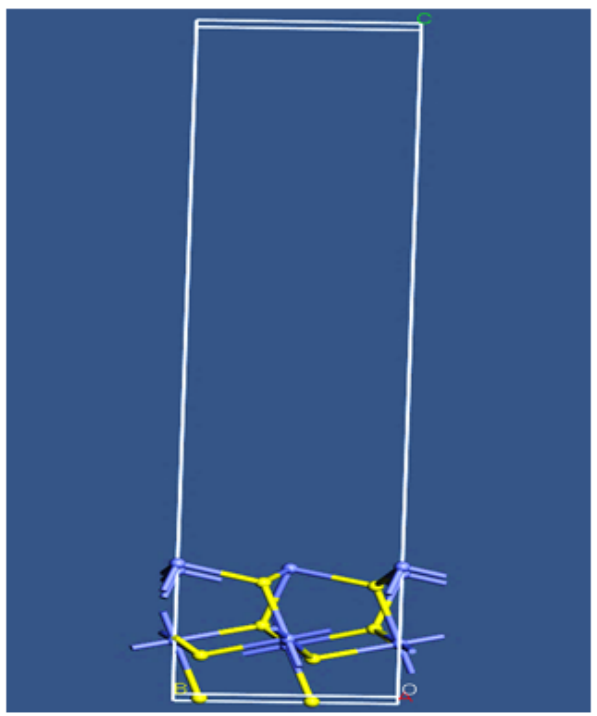

(a) Pyrite (200) surface

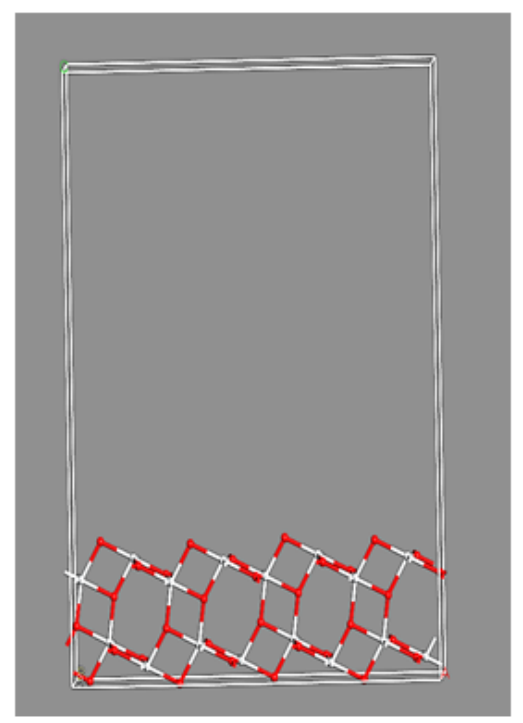

(b) Anatase (101) surface

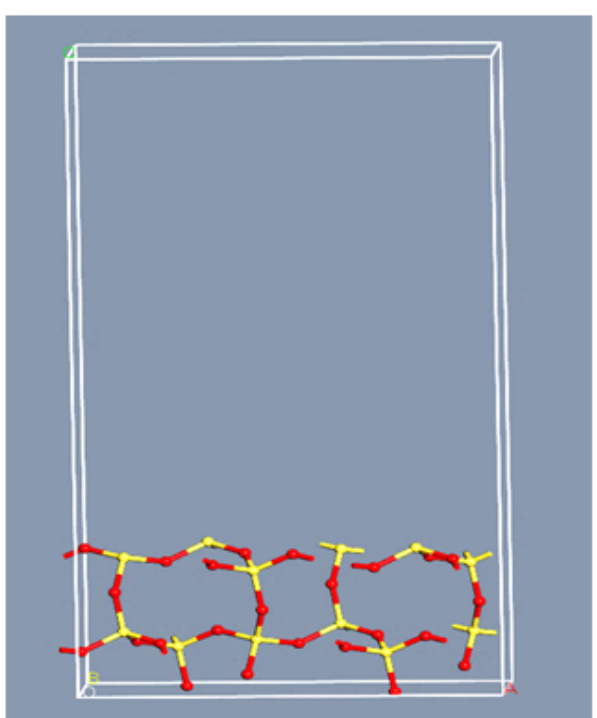

(c) Quartz (101) surface

Figure 5

Models of Crystal planes for different impurities in coal-series kaolin

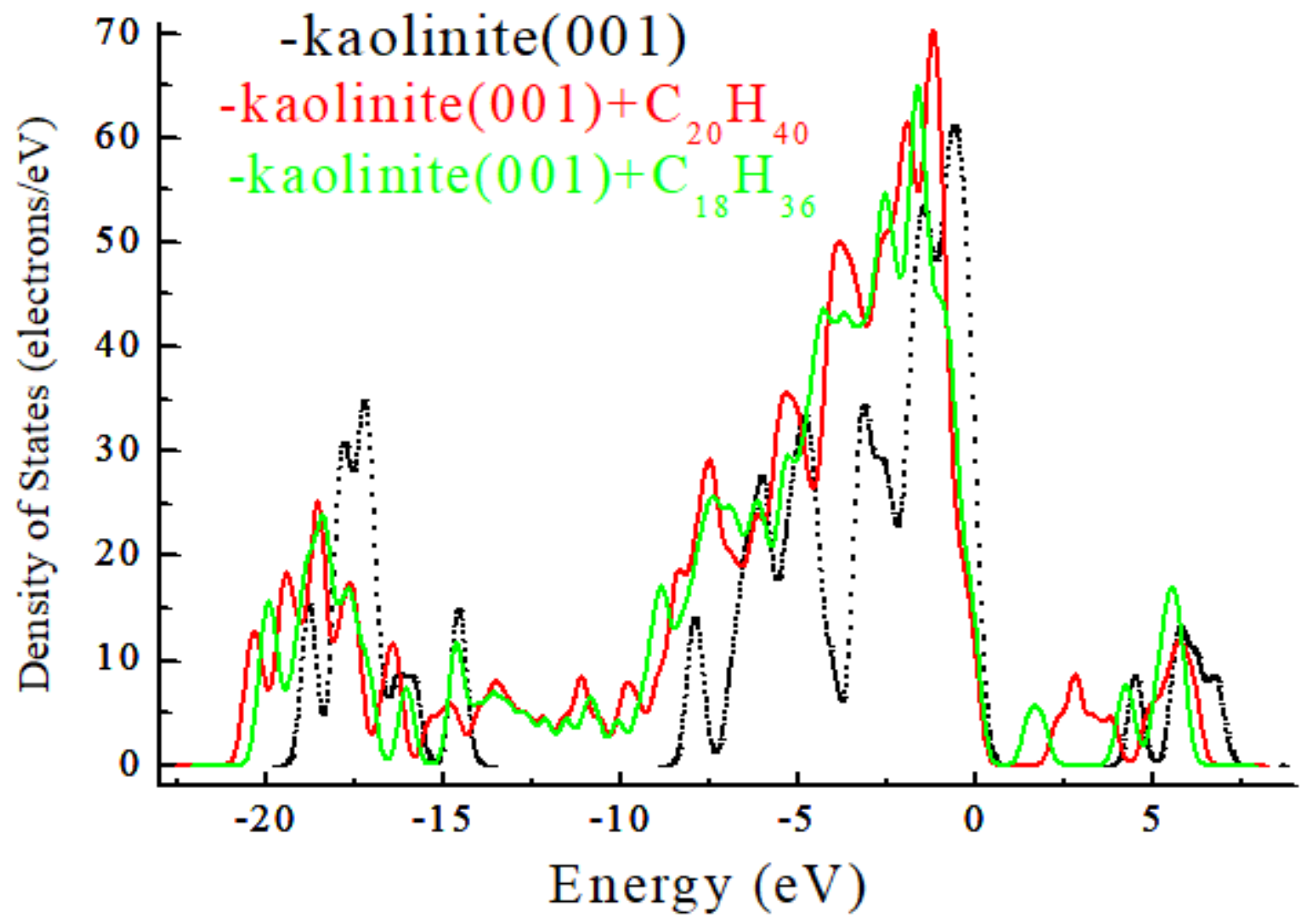

Figure 6

Comparison of DOS for kaolinite $₫ 001 \rrbracket a d s o r b e d$ with different organic molecules 


\section{Supplementary Files}

This is a list of supplementary files associated with this preprint. Click to download.

- Appendix.doc 